\title{
Nuevas formas de habitar la ciudad: hacia una conceptualización de la ciudadanía biovigilante
}

\author{
Enrique Baleriola, ${ }^{\star}$ Francisco Tirado, Marco Maureira, Pedro Torrejón \\ Universitat Autònoma de Barcelona, Barcelona, España
}

\begin{abstract}
Resumen
El concepto de ciudadanía es seguramente, uno de los más estudiados en la historia desde una perspectiva social: desde Aristóteles y la polis griega hasta la ciudad liberal del siglo XX. En este sentido, posteriormente han emergido una serie de estudios como los de Nikolas Rose o Kezia Barker donde el énfasis es puesto en la biociencia y la biotecnología para entender al ciudadano y donde el apego a un territorio ya no es una característica importante para la ciudadanía. En este trabajo, nos adherimos a esta línea y presentaremos el concepto de ciudadanía biovigilante para enmarcar una serie de políticas, acciones y acontecimientos que rodean a la ciudad actual en un campo donde los estudios sociales no han llegado con intensidad: la biovigilancia y las prácticas de bioseguridad en nuestra vida cotidiana. Mediante un estudio de caso de material documental sobre biovigilancia, presentaremos la novedad de nuestro trabajo frente a otras propuestas como las ya mencionadas utilizando de soporte teórico el concepto de paraskeue (equipamiento) de Michel Foucault. Finalmente, discutiremos acerca de las implicaciones biopoliticas de este nuevo tipo de ciudadanía y resaltaremos la importancia del concepto de escenario en las políticas de biovigilancia.
\end{abstract}

Palabras clave: ciudad; biovigilancia; equipamiento; preparedness; escenario.

\section{New forms to inhabit the city: towards a biowatcher citizenship}

\begin{abstract}
The citizenship concept is probably, one of the most studied along the History from a social perspective: from Aristoteles and the Greek polis until the liberal city of the 20th Century. In this sense, it has been recently emerged several studies such as the Nikolas Rose or Kezia Barker works highlighting key role of bioscience and biotechnology in order to understand the citizen without pointing out the link with a concrete territory. In this paper, we will be linked with this line and we will present the biowatcher concept in order to frame many politics, actions and events around the contemporary city in a field where the social studies has not arrive deeply: biosurveillance and biosecurity practices in our daily life. Through a study case with documentary material about biosurveillance, we will present the difference in our work with the other mentioned proposals using the paraskeue (equipment) concept given by Michel Foucault. Finally, we will discuss about the biopolitics consequences within this new kind of citizenship and we will put forward the value of the scenario concept in the biosurveillance politics.
\end{abstract}

Keywords: city; biosurveillance; equipment; preparedness; scenario.

El banóptico es sólo un modo de pensar la vigilancia, en el que los instrumentos de vigilancia se dedican a mantener lejos, en vez de mantener dentro, como hacía el panóptico, y que se nutre y crece con el imparable crecimiento de las preocupaciones securitarias...

Zygmunt Bauman

\section{Introducción}

Según algunos autores (RABINOW; BENNET, 2012; ROSE, 2006), la característica esencial de nuestra contemporaneidad es el auge de las denominadas ciencias bio. El uso del Big Data en la nueva medicina para el análisis de ingentes cantidades de datos; la aparición de mercados económicos biológicos, los avances científicos con el ADN humano o los organismos modificados genéticamente, la emergencia de nuevos bioriesgos con escala global (ataques de ántrax, epidemias como el $\mathrm{N} 1 \mathrm{H} 1$ o el ébola), o los fármacos y vacunas de última

\footnotetext{
^Esta investigación se ha realizado en el marco del programa de doctorado de Departamento de Psicologia Social de la Universitat Autónoma de Barcelona. Simultáneamente, el trabajo se enmarca en el proyecto de investigación "Salud y tecnociencia. La participación ciudadana en los procesos de apropiación social del conocimiento y de diseño tecnológico" financiado por el Ministerio de Economía y Competitividad del gobierno de España (CSO2014-59136-P). $\star \star$ Dirección de envío: Dep. de Psicologia Social - Fac. de Psicologia, Edifici B, Campus de Bellaterra. 08193 Bellaterra. 935813831. E-mail: ebebaes@ gmail.com, franciscojavier.tirado@uab.cat,marco.maureira@e-campus.uab. cat, ptorrejoncano@gmail.com
}

generación son eventos que caracterizan esa contemporaneidad, y tienen repercusiones no exclusivamente científicas puesto que implican en cursos de acción común a ciudadanos, instituciones internacionales, gobiernos y organismos locales.

Dentro de la anterior lista, destacan los fenómenos vinculados con las prácticas de bioseguridad y biovigilancia. La primera, siguiendo a Samimian-Darash (2009), se encargaría de las reglas y directrices que guían el contacto con agentes biológicos infecciosos y donde existe un riesgo que vulnera la seguridad de las personas. La segunda, en cambio, consistiría en la monitorización del movimiento de distintos agentes infecciosos con el fin de contenerlos y evitar la emergencia de una epidemia conocida o brotes desconocidos.

Ambas, biovigilancia y bioseguridad, se han convertido en fenómenos tan relevantes en nuestro presente que diversos autores sostienen que asistimos a un cambio de paradigma en la lógica de gobierno sobre las poblaciones para hacer frente a las amenazas desconocidas (BRAUN, 2007; COLLIER, 2008; COLLIER; LAKOFF; RABINOW, 2004; DOBSON; BARKER; TAYLOR, 2013; LAKOFF, 2006, 2008, 2009; LAKOFF; COLLIER, 2008). Esta nueva racionalidad de gobierno recibe la denominación de preparedness (preparación) y consiste en una intervención sobre la amenaza antes de que esta 
tenga lugar. Esto es, en una preparación presente para un posible (bio)riesgo futuro. Éste es concebido como una amenaza que puede aparecer en cualquier momento, en cualquier lugar del globo, con características nunca antes vistas y con repercusiones en una escala planetaria. Por ejemplo, un nuevo virus infeccioso para los humanos fruto de la mutación de otro en un reservorio de murciélagos en África, cuya transmisibilidad aérea es muy elevada.

La intervención sobre el riesgo desde la preparedness se lleva a cabo mediante la movilización de una gran infraestructura burocrática, institucional, política científica y social en diferentes escalas. Claramente se observa que desde la creación de leyes y normas internacionales por organismos como la Organización Mundial de la Salud (WORLD HEALTH ORGANIZATION, 2008) o la Organización de las Naciones Unidas para la Alimentación y la Agricultura (FOOD AND AGRICULTURE ORGANIZATION OF THE UNITED NATIONS, 2007); hasta la modificación ipso facto de protocolos por hospitales que manejan enfermedades infecciosas como el ébola, pasando por la creación de decálogos de información ciudadana (GENERALITAT DE CATALUNYA, 2015), la preparedness supone la articulación de multitud de actores dispares y escalas diferenciadas en cursos de acción comunes y con un único sentido.

En la línea de los trabajos que aúnan epidemias con cuestiones de carácter sociopolítico (INGRAM, 2013; LAKOFF, 2008, 2009), en estas páginas presentamos un análisis de la transformación que sufre el papel de la población en el paradigma de la preparedness. Argüiremos en ese sentido que la noción pierde su fuerza originaria y deja paso a una nueva lógica que hemos denominado "ciudadanía biovigilante". El concepto refleja la creación de un modo de subjetividad que resulta de las prácticas de control, monitorización y management de enfermedades infecciosas. Para hacer tal cosa, en primer lugar, hablaremos del concepto de ciudadanía desde una perspectiva tradicional. En segundo, expondremos los nuevos tipos de ciudadanías emergidos a raíz de los acontecimientos contemporáneos comentados anteriormente. Estos son la Ciudadanía Biológica de Adriana Petryna o Nikolas Rose y la Ciudadanía Biosegura de Kezia Barker. A partir de los esbozos de estos trabajos y con material de una investigación realizada en los dos últimos años sobre bioseguridad y situaciones de emergencia biológica en la Unión Europea, plantearemos que ha emergido un nuevo tipo de ciudadano que denominaremos "ciudadanía biovigilante".

\section{2. ¿Qué es la ciudadanía?}

La palabra ciudadanía se vincula habitualmente a la noción de ciudad y se considera que la primera es cualidad y producto de la segunda: "La ciudad es una mezcla compleja de fenómenos diarios que ocurren simultáneamente en espacios alejados, una fusión de aspectos culturales que el tiempo ha venido a fijar en actitudes y formas de vida propias de una localidad concreta" (FERNÁNDEZ-RAMÍREZ, 2010, p. 241).

Fractal, Rev. Psicol., v. 28 - n. 2, p. 172-180, 2016
De origen latino, "conjunto de todos los ciudadanos", pero también, "cualidad de derecho de ciudadano" formado en base al sufijo civitas- (ciudadanía romana), y los sufijos -anus (pertenencia), -ia (cualidad) ${ }^{1}$ denota la pertenencia a una comunidad políticamente articulada, en base a una ciudad que se inserta en un territorio, nación o país particular.

La definición de ciudadanía ha generado verdaderos ríos de tinta y formulaciones No obstante, toda esa literatura se puede agrupar en tres grandes visiones o marcos de análisis: la republicana, la liberal, y la marxista.

El origen de lo que hoy en día entendemos por ciudadanía se remonta a la visión republicana de la Antigua Grecia y el significado originario de la palabra democracia (demos- cuyo significado es pueblo, y kratos, poder) aplicado a las ciudades-estado (polis) que la componían, y que después se ampliará durante la configuración del Imperio Romano a una posición de derechos y deberes.

Durante este periodo, Aristóteles (1988, nuestra traducción) definirá al ciudadano como "la persona que participa del gobernar y del ser gobernado, en cada régimen es distinto, pero en el mejor es el que puede y elige obedecer y mandar con miras a una vida conforme a la virtud", siendo esta concepción la que ha llegado hasta nuestros días como el ideal del ciudadano activo, del cual emanan las leyes puesto que participa en su elaboración y su mantenimiento. Bajo la concepción de Aristóteles de la ciudadanía, hombre y ciudadano son homónimos, puesto que como argumenta Peña (2003, p. 240), el hombre se concibe como alguien "que se entiende a sí mismo en relación con la ciudad, porque considera que la garantía de su libertad estriba en el compromiso con las instituciones republicanas y el cumplimiento de sus deberes para con la comunidad".

Hobbes fundará en las postrimerías del renacimiento una nueva manera de entender la ciudadanía que será considerada el embrión de la perspectiva liberal. Según ésta, el ciudadano es entendido como un ser que goza de gran autonomía gracias a la intervención mínima de la política y de otros ciudadanos sobre su quehacer. En palabras del propio Hobbes (2002, p. 19): "se entiende por libertad, según el más propio significado de la palabra, la ausencia de impedimentos externos". Con esta sentencia entendemos la diferencia en la concepción ciudadana respecto a la visión republicana, y es que lo importante ya no es tanto la participación activa en la democracia, sino el libre laissez-faire y la protección de las libertades del ciudadano, papel que debe cumplir el Estado. Por tanto, se rompe la equivalencia entre hombre y ciudadano, ya que bajo la visión liberal primero se es hombre antes que ciudadano: el hombre es portador de derechos, la ciudadanía solo es el reconocimiento de estos derechos (AYALA; LEETOY, 2011).

Más recientemente, y en la línea del liberalismo político, se encuentra el trabajo de Marshall (1950, p. 28, nuestra traducción) el cual argumenta que la ciudadanía consiste en: "un estatus conferido a aquellos que

${ }^{1}$ Análisis facilitado por la página web $<$ http://etimologias.dechile.net/>. 
son miembros plenos de una sociedad". La novedad de Marshall consiste en dotar a la ciudadanía de tres características forjadas a lo largo de los siglos XVIII-XX: la civil, la política y la social. Estos elementos, según Ayala y Leetoy (2011, p. 134) consistirían en:

Los derechos necesarios para la libertad individual: la libertad de la persona, de expresión, de pensamiento y religión, derecho a la propiedad y a establecer contratos válidos y derecho a la justicia [...] Por elemento político entiendo el derecho a participar en el ejercicio del poder político como miembro de un cuerpo investido de autoridad política, o como elector de sus miembros. El elemento social abarca todo el espectro, desde el derecho a la seguridad y a un mínimo bienestar económico al de compartir plenamente la herencia social y vivir la vida de un ser civilizado conforme a los estándares predominantes en la sociedad. Las instituciones directamente relacionadas son, en este caso, el sistema educativo y los servicios sociales.

En último lugar, tenemos la visión marxista. A partir de los fenómenos urbanos que ocurren durante el siglo XIX como pueden ser el éxodo rural, la masificación de las ciudades, el hacinamiento como consecuencia de la primera Revolución Industrial, etcétera, Marx critica el concepto de ciudadanía de la visión liberal y del contrato social, y plantea que ambas solo consideran ciudadano al varón propietario y no a todos los miembros de la sociedad (PELÁEZ, 2009, p. 45). Por tanto, el sujeto de todos los derechos políticos de los que habla Marshall no representa al conjunto social, sino solamente a la burguesía propietaria, falseando la realidad social de la época y utilizándose como un mecanismo de poder más sobre el proletariado y los trabajadores.

\section{Nuevas ciudadanías}

En las últimas dos décadas y desde disciplinas tan diferentes como la geografía, la antropología o los estudios sociales de la ciencia y la tecnología se han desarrollado interesantes críticas a las mencionadas perspectivas que han desembocado en lo que podemos denominar "nuevas ciudadanías". En éstas se combinan dos grandes dimensiones. Por un lado, el interés por la gestión y gobierno de las grandes poblaciones y, por otro, el papel que juegan en éste los dispositivos biocientíficos y económicos. Como argumenta Ong (2006), los mercados financieros y las nuevas tecnologías cristalizan los cambios en la ciudadanía actual. Las ciudades diluyen sus fronteras y aparecen los neticens, esto es, los ciudadanos del ciberespacio. La característica fundamental de todas estas nuevas formas de ciudadanía en contraste con las que hemos visto hasta ahora, reside en la poca importancia que se otorga a la vinculación de las personas con un territorio concreto en la definición del ciudadano.

Entre las propuestas de "nuevas ciudadanía" más interesantes destacan la de ciudadanía biológica de Nikolas Rose y Carlos Novas, por un lado, y la de Adriana Petryna, por otro; también merece especial mención la réplica de Bruce Braun a la propuesta de Rose y Novas, y en último lugar, la afirmación de Kezia Barker sobre la aparición de una ciudadanía biosegura.

\subsection{Ciudadanía biológica}

La ciudadanía biológica de Rose y Novas surge a partir del auge de las disciplinas biomédicas, biotecnológicas y de la genética. Según estos autores, durante los siglos XIX y XX, aparecen distintos proyectos ciudadanos dentro de la historia política (ROSE; NOVAS, 2003) cuya finalidad es entender las formas por las que las autoridades han pensado sobre ciertos individuos como potenciales ciudadanos y las formas por las que aquellas intentaron actuar sobre estos (ROSE; NOVAS, 2003, p. 1). Algunos de estos proyectos son la imposición de hablar una sola lengua nacional, o la planificación arquitectónica y urbanística que promueve ciertas formas concretas de pensar, sentir y actuar

La ciudadanía biológica se entendería como uno de estos proyectos que han unido la concepción de ciudadanía a las creencias acerca la existencia biológica de seres humanos como individuos, familias, linajes genéticos, comunidades, razas y especies, transformándose y reconfigurándose las especificidades de este binomio en función de las peculiaridades del territorio donde se conceptualiza la ciudadanía biológica.

En este sentido, Rose y Novas argumentan que en la actualidad, estos proyectos de ciudadanía biológica son diferentes de los temas concebidos durante la primera mitad del siglo XX (campos de concentración, diferencias genéticas raciales y por género), centrándose en otro tipo de cuestiones como el aborto selectivo o la selección de embriones. Se trataría, entonces, de la incorporación de lo corpóreo a las prácticas de identidad con ayuda de la tecnología, desde lo macro (cirugía estética) hasta lo micro (genes) (ROSE; NOVAS, 2003, p. 3).

Este tipo de proyectos estarían dando lugar a un ciudadano mediante nuevos discursos y dilemas éticos a partir de los cuales deberá regular su vida individual sobre aspectos que hasta hace pocos años se consideraban parte del destino y sobre los que ahora podemos intervenir (ROSE; NOVAS, 2003, p. 36). La vida, en un sentido puramente biológico, se vuelve objeto de cuestión ética y también económica: la vida y los cuerpos pueden ser manipulados para incrementar su valor, adquiriendo el ciudadano un nuevo ethos basado en los avances de las ciencias del bios. Los límites que definen aquello que se considera humano, se encuentran redefinidos en la actualidad.

Otros autores, como Petryna (2004), han incidido también en la noción de ciudadanía biológica. Para esta autora, la pregunta fundamental en relación con este concepto tiene que ver con el valor de riesgo que adquiere la vida en la nueva hegemonía de las ciencias de la vida. A diferencia de Rose y Novas, ella, analizando el accidente de Chernóbil, adhiere al ciudadano biológico el componente de manejo del riesgo de posibles catástrofes futuras que es el resultado no solo del conocimiento biomédico experto, sino también de las decisiones políticas que cada Estado nacional toma.

El ciudadano biológico no tiene una definición exacta, sino que más bien es el resultado de un conjunto de prácticas socio-políticas de un lugar y momento determinado, 
que tienen que ver con la salud y la seguridad biológica. Esta ciudadanía será gestionada en base a los intereses económicos y políticos, los cuales están cada vez más dirigidos desde las esferas de conocimiento biológicas y se crean nuevas formas de poder. Este poder, a diferencia de la propuesta de Rose y Novas, donde el cuerpo era molecularizado en pequeños elementos, en Petryna (2004, p. 262) se encuentra numerificado y convertido en datos:

Aware that they had fewer chances for finding employment and health in the new market economy, these citizens accounted for elements in their lives (measures, numbers, symptoms) that could be linked to a state, scientific, and bureaucratic history of mismanagement and risk. The tighter the connection that could be drawn, the greater the chance of securing economic and social entitlement. ${ }^{2}$

En una línea similar a la anterior, BRAUN (2007, p. 7) recupera los trabajos de Deborah Heath, Rayna Rapp y Karen-Sue Taussing (2004) para conceptualizar lo que ellos denominan ciudadanía genética:

$[\ldots]$ Indeed, as numerous commentators have noted, in the wake of new reproductive technologies, stem cell research and other biotechnological advances, there have emerged countless new forms of 'genetic citizenship', by which individuals and groups have made their biological existence a matter of ethical concern and a basis for political action. ${ }^{3}$

En ese sentido, Braun (2007, p. 12) afirma que se nos pide y exige ser ciudadanos genéticos, lo cual significa que estamos obligados a gestionar de manera acertada e informada nuestras vidas a través de un ejercicio permanente de elección. Braun afirma que no podemos, como argumentan Rose y Novas, reducir la biopolítica a las acciones alternativas que los ciudadanos llevan a cabo para empoderarse o quedarse atrapados en la red del poder pastoral dentro del neoliberalismo de la vida molecularizada: la teoría de la gubernamentalidad o de la autogestión tiene límites. La alternativa de Braun consiste en plantear las acciones referidas a la bioseguridad como una serie de respuestas políticas dentro de la globalización, que toman la impredictibilidad de la vida molecular como su propia justificación, y de esta forma, la seguridad aparece como la única respuesta política posible (BRAUN, 2007, p. 15).

\subsection{Ciudadanía biosegura}

En relación con la noción de seguridad, destaca por su interés la propuesta de Kezia Barker. Su proposición alude a una esfera particular de las nuevas ciencias de la vida y que detentaría un nacimiento relativamente reciente, nos referimos a la bioseguridad. Analizando las características de las políticas de bioseguridad que se han implementado en las dos últimas décadas, la autora sos-

\footnotetext{
${ }^{2}$ Conscientes de que tienen pocas oportunidades para encontrar empleo y salud en la nueva economía de mercado, estos ciudadanos consideraban elementos en sus vidas (medidas, números, síntomas) que podrían estar ligados a un estado, a una historia científica y burocrática de mala gestión y de riesgo. Cuanto más estricta es la conexión que puede ser esbozada, más grande es la oportunidad de conseguir seguridad económica y derechos sociales.

${ }^{3}$ De hecho, como muchos comentaristas han apuntado, en el despertar de las nuevas tecnologías de reproducción, la investigación con células madre y otros avances biotecnológicos, han emergido incontables formas nuevas de "ciudadanía genética" por las cuales los individuos y los grupos han hecho de su existencia biológica un asunto de preocupación ética y una base para la acción política.
}

tiene que ha emergido un nuevo tipo de ciudadanía que se puede denominar "ciudadanía biosegura". Las características principales de este tipo de ciudadano son, siguiendo a Barker (2010, p. 351):

a) La gestión no recae exclusivamente sobre el cuerpo (como puede ser el caso de la ciudadanía biológica de Rose y Novas), sino en las conexiones de este con otras entidades humanas y no humanas.

b) Debido a esto, el cuerpo se concibe como un organismo simbiótico, en contacto continuo con otros organismos: si el ciudadano se desplaza, también se desplazan los virus y bacterias que este porta. El cuerpo debe ser gestionado por el Estado: Due to the capacity our symbiotic associations with other species have for enabling the dangerous mobility of biological life, these associations have been politicised as matters of state concern and made subject to biosecurity control. ${ }^{4}$

c) Las leyes, normas y conocimientos acerca de la cuestión de la bioseguridad, reconfiguran la definición de la simbiosis inter-especie, lo que justifica la entrada del estado en el ámbito privado y personal.

Como se puede apreciar, Barker otorga a los Estados nacionales convencionales un rol principal y básico en la gestión de los cuerpos que va más allá de la propuesta de Rose. Ésta, anclada en una concepción excesivamente molecular de la vida, soslaya tanto las relaciones que se establecen entre diferentes especies biológicas como entre actores ontológicamente diferentes. Por ejemplo, no se atiende a la relevancia de un avión en el que viaja un mosquito con un virus que nunca antes había aparecido en un país, o al impacto de la importación de un tipo de fruta inexistente en un área geográfica determinada.

\section{Hacia una ciudadanía biovigilante}

Como hemos visto a lo largo de los anteriores apartados, en los últimos años el concepto de ciudadanía se ha vinculado estrechamente con una conciencia biológica activa de uno mismo y con una comprensión microbiótica amplia del medio. No obstante, todas las propuestas mencionadas adolecen de una carencia. Olvidan sistemáticamente el papel que desde la irrupción de las prácticas de bioseguridad en nuestra vida cotidiana ha adquirido el fenómeno de la biovigilancia. A continuación, a partir de una investigación realizada en los dos últimos años sobre los discursos y prácticas de bioseguridad que se han implementado en la Unión Europea, mostraremos cómo ha emergido un nuevo tipo de ciudadanía que denominaremos "biovigilante" y cuáles son las principales características que la conforman.

\subsection{Bioseguridad, escenarios y equipamiento}

La bioseguridad aparece siempre vinculada a la formulación y definición de lo que los epidemiólogos denominan escenarios ${ }^{5}$ Éstos básicamente remiten a dos

${ }^{4}$ Debido a la capacidad de nuestras asociaciones simbióticas con otras especies para permitir la peligrosa movilidad de la vida biológica, estas asociaciones han sido politizadas como asuntos de interés del Estado y se han hecho sujeto de control de la bioseguridad.

${ }^{5}$ Ejemplos de lo mencionado se pueden encontrar en O’Toole (1999) y Khan (2011). 
tipos de marcos de acción. En primer lugar tenemos simulaciones de situaciones de emergencia posibles en las que se manipula una o varias variables como amenazas y se plantea el interrogante de cómo éstas transformarían un contexto social, político y material. Las amenazas pueden ser reales, como es caso de virus como la viruela o el ébola, o completamente ficticias, como ocurre en algunos escenarios que se plantea la hipótesis de una invasión zombi o alienígena. En segundo, existe una serie de documentos como protocolos de intervención médica, artículos científicos o manuales de instituciones sanitarias que establecen medidas de actuación, de organización de servicios, higiene personal o relaciones sociales y biológicas que delimitan cómo debe ser el comportamiento individual y colectivo en el caso de situaciones de bioriesgo. En este sentido, autores como Zylberman (2013) han planteado que un escenario debe ser entendido como una imitación de una situación excepcional y ficticia que pretende mejorar el control de la misma con la finalidad de que los sujetos aprendan por primera vez los procedimientos que tendrán que llevar a cabo si este tipo de situación ficticia se produjese efectivamente en su cotidianeidad.

Para entender qué supone el tipo de conocimiento y prácticas que aportan los escenarios, hemos recurrido a la noción de "equipamiento". La noción proviene del trabajo de Foucault (paraskeue) y en palabras de este autor (FOUCAULT, 1994, p. 307) se define del siguiente modo:

La askesis, en razón de su objetivo final, que es la constitución de una relación de sí consigo plena e independiente, tiene esencialmente por función, por objetivo primero, la constitución de una paraskeue (una preparación, un equipamiento). ¿Y qué es esa paraskeue? Es, creo, la forma que deben asumir los discursos de verdad para poder constituir la matriz de los comportamientos racionales. La paraskeue es la estructura de transformación permanente de los discursos de verdad [...] es el elemento de transformación del logos en ethos. Y entonces puede definirse la askesis: será el conjunto, la sucesión regulada, calculada de los procedimientos que, en un individuo, son susceptibles de formar, de fijar definitivamente, de reactivar periódicamente y de reforzar si es necesario esa paraskeue.

Un equipamiento o paraskeue estaría formado por a) un logos, b) un acontecimiento, c) un ethos y d) una subjetividad que aparece como vínculo de los anteriores elementos.

El logos aparece como el discurso de todos los elementos que hemos analizado. Desde un punto de vista semiótico-material simétrica (BLOOR, 1995), el discurso no es entendido exclusivamente como la performatividad que se desprende de un determinado lenguaje oral o escrito. Más bien, entendemos los elementos aquí analizados como una tecnología mediadora (LATOUR, 2001) y por este motivo, consideramos que el equipamiento no es exclusivamente lingüístico: la interacción de una persona que observa una pancarta anunciando una app con la que alertar a la red centinela de bioseguridad cuando tenga fiebre, es un evento que incluye muchos más elementos y acciones que las que el lenguaje puede proveer en sí mismo. En este sentido, el logos de la bioseguridad alude directamente a la necesidad de vigilar las enfermedades infecciosas por parte de los ciudadanos. En este sentido, entendemos por ciudadano aquella persona no experta en temas de biovigilancia o bioseguridad, pero que es equipada por estos elementos en su día a día.

En segundo lugar, el acontecimiento se define, en palabras de Tirado (2001, p. 130) como un dis-curso:

Tenemos una situación, estamos inmersos en una relación, lo que sea. Posee un sentido, único, significado privilegiado [...] De pronto, aleatoriamente se produce en la situación o relación una perturbación, división, movimiento ínfimo en la dirección o sentido y aparece un dis-curso. Adviene una derivación, una bifurcación. Ahora hay dos sentidos, diferencia, novedad, la situación o relación experimenta un cambio. Se ha dado una inclinación del sentido que altera la situación. Estamos ante una declinación, aparece una duda.

El acontecimiento en el equipamiento de la bioseguridad hace referencia a diversas cosas: la persona que va andando por un aeropuerto internacional y se topa con una persona que percibe como perteneciente a una zona en que existen brotes epidémicos vomitando en un pasillo: ¿se acerca a ayudarle o se aleja por si se trata de ébola?; el familiar que se encuentra con dolores de cabeza y fiebre desde que volvió de una hot zone la semana pasada ¿debe acudir al médico?; el grupo de amigos que planea un viaje a África: ¿debe hacer caso al mapa epidemiológico que indica un alto riesgo de contraer malaria?

Por último, el ethos consiste en "la manera de ser, el modo de existencia de un individuo" (FOUCAULT, 1994: 227). Foucault indica que el ethos es creado o modificado por un logos en particular. En la bioseguridad, el logos consiste en las circunstancias y los saberes que unen el conocimiento biotecnológico y biocientífico a la ciudad. De este logos se desprenden unas acciones concretas (ethos); por ejemplo, no viajar a África tras consultar el mapa epidemiológico por Internet o vacunarse antes de viajar a India por el posible riesgo de infección de una enfermedad tropical.

Cuando el equipamiento es normalizado por el ciudadano, de manera que la persona naturaliza la acción de vacunarse antes de viajar al extranjero, o de alertar a ciertas instituciones de unos extraños síntomas, emerge el ciudadano biovigilante como una subjetividad de la ciudadanía contemporánea de Occidente. Esto ocurre gracias a que el equipamiento porta, implícitamente, un régimen de veridicción el cual "es necesario para que los discursos de verdad puedan constituir la matriz de los comportamientos racionales, ya que es el elemento de transformación del logos en ethos" (FOUCAULT, 1994, p. 307). La última característica resaltable de este logos, es que se trata de un logos boethos (FOUCAULT, 1994, p. 304), esto es, de auxilio, ya que es el que te dice cómo se debe comportar el ciudadano (cómo debe ser su ethos) cuando ocurre un acontecimiento biológico, esto es, en momentos de duda o cuando la persona se siente amenazada. 
Por tanto, forman parte del equipamiento de la bioseguridad materiales tan diversos como mapas, noticias en prensa, anuncios, decálogos y trípticos informativos de gobiernos o información de internet a la cual cualquier persona puede acceder fácilmente.

\subsection{Ciudadanía biovigilante}

A continuación mostraremos algunos ejemplos que ilustran todo lo mencionado en el apartado anterior y que nos ayudan a tematizar la noción de "ciudadanía biovigilante". En primer lugar, y en relación con el logos que aparecen en todo equipamiento, quisiéramos pedir al lector que observe atentamente la siguiente imagen: break reports on the interactive map, and set the app to alert you with a notice when an outbreak is occurring in your area. If you spy an outbreak, be the first to report it using the app's unique outbreak reporting feature. You will get credit as a disease detective and your find will be featured on HealthMap's website. ${ }^{6}$

Extraído de: <http://www.healthmap.org/outbreaksnearme/>

Esta aplicación nos muestra cómo la cotidianidad del ciudadano que se encuentra paseando, en el metro rodeado de personas o en el centro comercial; se puede ver alterada de súbito por lo que ocurre a su alrededor. Las fuentes de información oficiales (instituciones públicas reconocidas, laboratorios, prensa) no son las únicas que alertan al residente, sino que existen fuentes de información "extra-oficiales" que toman la función de monitorización y ofrecen una geolocalización de la amenaza biológica.

En el mismo instante en que el sujeto es avisado por HealthMap, se produce el acontecimiento, es decir, aparece la escisión, la duda, el dis-curso mencionado anteriormente. La situación es atravesada por el acontecimiento de forma atemporal: no existe un momento o unas circunstancias específicas para que la alerta aparezca, sino que esta emergen cuando es detectada por la aplicación.

Este flujo de información y esta escisión del acontecimiento tienen un efecto sobre el ethos, cuya fuente es el logos que rodea a los objetos semiótico-materiales que hemos ilustrado en el punto anterior con la imagen de la Organización Mundial de la Salud. El ciudadano, ya no cuenta solo con la información de cómo "prevenirse", sino también cuenta con la información de dónde prevenirse, hacia dónde no ir, etcétera. El acontecimiento transforma la cotidianidad diaria de los habitantes y les proporciona una aparente mayor seguridad frente a las amenazas biológicas.

Y por último, y en relación con el ethos, atendamos a estas afirmaciones:

How do I add alerts?

To add an alert, click on this icon. Complete the top part of the form if there is a URL of a news story about an outbreak

${ }^{6}$ Con la aplicación de HealthMap, "Outbreaks Near Me", tienes en tiempo real información sobre brotes de enfermedades en tus manos. Abre la aplicación y mira todos los brotes actuales en tu barrio, incluyendo noticias sobre la gripe H1N1 (fiebre porcina). Busca y envía informes sobre brotes en el mapa interactivo, y configura la aplicación para alertarte con una noticia cuando un brote esté ocurriendo en tu zona. Si persigues un brote, sé el primero en alertar usando la característica de la aplicación para alertar. Serás acreditado como un detective de enfermedades y tus indagaciones serán presentadas en la web de HealthMap. 
that you can specify. All you need to do is submit the URL; HealthMap will do the rest - extracting the disease and location from the story with our automated system, and placing it in the correct location on the map. You will receive an email with a link to edit that information if necessary.

To add an outbreak report of something you personally know about that has no supporting URL, complete the bottom half of the form, and submit. Our team of public health professionals will review your submission and add it to the map after they have deemed the report credible ${ }^{7}$.

Extraído de: http://www.healthmap.org/site/about/faq

En sentencias como esta aparece claramente el sustento del comportamiento o la manera de ser, en palabras de Foucault, de una ciudadanía biovigilante. El equipamiento es sustentado por el régimen de veridicción que otorgan tanto el discurso biomédico y de la salud; como las imágenes de un mapa global a tiempo real, donde las noticias y alertas son avaladas por un equipo de profesionales en salud pública.

Este régimen de veridicción, unido a la facilidad para conseguir la app y reportar una alerta epidémica utilizándola, hace que resulte muy fácil y atractivo que cualquier ciudadano actúe en consecuencia, preocupándose cuando varios individuos tosen a su alrededor en el metro o si en medio de una transcurrida avenida una persona con unas extrañas ampollas o erupciones en la piel le toca.

Los ejes que caracterizarían al ciudadano biovigilante serían los siguientes:

a) La vida es vigilada, pero también es vigilante: el nuevo ciudadano cumpliría una doble función, por un lado, es vigilante de lo vivo y, a la vez, es aquello que debe ser vigilado. Al contrario de las concepciones biopolíticas clásicas como la de Foucault, las personas que habitan un estado-nación o un territorio particular ya no solo son subjetivados en base a la estadística (mediante nacimientos y muertes por ejemplo), la policía u otras instituciones en el siglo XIX, o a otros diagramas de fuerzas en otras formaciones históricas (por ejemplo, el panóptico), sino que en el presente son ellos mismos parte activa del circuito de vigilancia y control.

b) La cualidad de la ciudadanía ha sufrido una importante transformación. Pasa de ser una condición absoluta que se detanta todo el tiempo a algo intermitente. Necesita un elemento que la active o la cierre. Y ese será el acontecer. Cuando aparece el mencionado dis-curso, cuando se introduce la novedad se despliega la nueva ciu-

\footnotetext{
¿Cómo puedo añadir alertas? Para añadir alertas, haz click en este icono. Completa la parte de arriba del formulario si hay una dirección URL del cuerpo de una noticia sobre un brote que puedas especificar. Todo lo que necesitas es rellenar la dirección URL, HealthMap hará el resto -extrayendo la enfermedad y la localización del cuerpo de la noticia con nuestro sistema automático, y poniéndola en la localización correcta del mapa-. Recibirás un email con un vínculo para editar la información si fuese necesario. Para añadir una alerta sobre un brote de algo que conoces personalmente y no tienes una dirección URL, completa la parte de abajo del formulario y envíalo. Nuestro equipo de profesionales de salud pública revisarán tu envío y lo añadirán al mapa después de considerar tu alerta creíble.
}

dadanía. Y es en ese preciso momento que devenimos auténticos vigilantes activos de nuevos focos infecciosos.

c) Como sostiene Michel Serres (2002), es importante diferenciar entre observación y vigilancia. En la segunda tenemos una mirada total y global, que opera desde fuera del objeto observado y que tiene la cualidad de definir en su complitud su objeto de mirada. En la observación tenemos una mirada que se realiza desde dentro del objeto mirado y por tanto es parcial y fragmentada. Pues bien, en el ciudadano biovigilante tenemos este tipo de mirada. Este nuevo tipo de ciudadano se encargaría de bio-observar, entendiéndose como una observación desde el interior de la propia dinámica de control de brotes infecciosos, con un contacto directo e inmediato con los distintos actores que conforman la trama del control de virus y pandemias.

d) Una última característica del ciudadano biovigilante la encontraríamos en el control que este posee sobre la información que produce, pero no sobre lo que ocurre después con esa información, es decir, sobre el conocimiento que generará después. Por tanto, es una entidad reflexiva y consciente de la información que genera pero carente de control sobre los últimos estadios en los que se implica esta última.

\section{Conclusiones}

Las nuevas ciudadanías establecen una profunda ruptura conceptual con la noción clásica. Si bien esta última vinculaba al ciudadano con una ubicación física (normalmente la ciudad) y un territorio, en las nuevas definiciones la población se vincula a dispositivos de control que se rigen a partir de criterios biocientíficos. En tales conceptualizaciones la noción de biopolítica se torna relevante. Pero, a su vez, se establece una distancia con la propuesta foucaultiana en la medida en que la corporeidad y la disciplina dejan paso al entrecruzamiento de bases de datos, sistemas monitorización y vigilancia a distancia.

En ese contexto las prácticas y discursos de la bioseguridad son especialmente interesantes porque revelan la aparición de nuevos tipos de vigilancia y la conformación de otro tipo de ciudadanía que va más allá de la meramente somática o biológica. Como hemos mostrado, el auge de la bioseguridad implica un incremento del uso de lo que la epidemiología denomina "escenarios de preparación" en las ciencias de la vida. Tales escenarios no son una simple simulación con variables estadísticas, índices de contagio, protocolos o cálculos de riesgo. Constituyen un conjunto de cursos de acción que despliegan un logos, un acontecimiento y un verdadero ethos. A este conjunto lo hemos denominado "equipamiento". Y en el caso de la bioseguridad, semejante equipamiento hace referencia a la aparición de un nuevo fenómeno: la biovigilancia.

Fractal, Rev. Psicol., v. 28 - n. 2, p. 172-180, 2016 
Este equipamiento al desplegarse en nuestra vida cotidiana permite la aparición de un nuevo tipo de ciudadano que hemos denominado "biovigilante".

Finalmente, hemos esbozado lo que sería la silueta de este nuevo ciudadano biovigilante. La vida ya no solo es vigilada y controlada, sino que se pide al ciudadano que tome un papel activo en este proceso y vigile en tanto que sea vigilado. Además, siguiendo la teoría foucaultiana sobre equipamiento, este requerimiento sería totalmente efectivo ante la irrupción del acontecimiento, ante el evento inesperado que introduce una novedad. La biovigilancia por tanto, tendría lugar en un proceso llevado a cabo desde el interior de la propia dinámica de monitoreo puesto que el ciudadano actuaría en el momento en que percibe a una persona extraña que sangra, vomita o palpita; o ante la alerta del smartphone por la aparición de un brote epidémico en la ciudad de residencia. Por último, nos enfrentaríamos ante una controversia acerca de la condición democrática de este tipo de participación en la actividad de vigilancia: el ciudadano juega el rol de alerta y reporte de un nuevo brote pero, ¿qué ocurre después con esa información? ¿Quién la maneja? ¿Con qué finalidad es empleada? ¿Qué implicaciones biopolíticas (en un sentido no exclusivamente Foucaultiano) conlleva?

\section{Referencias}

ARISTÓTELES. Política. Madrid: Gredos, 1988.

AYALA, P.; LEETOY, S. Repensar la ciudadanía: los desafíos de un nuevo pacto global. Guadalajara: Instituto Tecnológico y de Estudios Superiores de Monterrey, 2011.

BARKER, K. Biosecure citizenship: politicising symbiotic associations and the construction of biological threat. Transactions of the Association of British Geographers, v. 35, n. 3, p. 350-363, July 2010.

BLOOR, D. Conocimiento e imaginario social. Barcelona: Gedisa, 1995.

BRAUN, B. Biopolitics and the molecularisation of life. Cultural Geographies, v. 14, n. 1, p. 6-28, 2007.

COLLIER, S. J. Enacting catastrophe: preparedness, insurance, budgetary rationalization. Economy and society, v. 37, n. 2, p. 225-250, 2008

COLLIER, S. J.; LAKOFF, A.; RABINOW, P. Biosecurity: towards an anthropology of the contemporary. Anthropology Today, v. 20, n. 5, p. 3-7, Oct. 2004.

DOBSON, A.; BARKER, K.; TAYLOR, S. H. Biosecurity: the socio-politics of invasive species and infectious diseases. London: Routledge, 2013.

FERNÁNDEZ-RAMÍREZ, B. El medio urbano. In: ARAGONÉS, J. I.; AMÉRIGO, M. (Coord.). Psicología Ambiental. Madrid: Pirámide, 2010.

FOOD AND AGRICULTURE ORGANIZATION OF THE UNITED NATIONS. FAO biosecurity toolkit. Rome: FAO, 2007.

FOUCAULT, M. La hermenéutica del sujeto. Madrid: La Piqueta, 1994.
GENERALITAT DE CATALUNYA. Decàleg sobre la Malaltia de'Ebola. 2015. Available at: <http://canalsalut.gencat.cat/ web/.content/home_canal_salut/professionals/temes_de_salut/ ebola/documents/decaleg_malaltia_ebola.pdf>. Access on: 10 Ago. 2015

HEATH, D.; RAPP, R.; TAUSSIG, K. Genetic citizenship. In: NUGENT, D.; VINCENT, J. (Ed.). A companion to the anthropology of politics. Malden, MA: Blackwell, 2004. p. 152-167.

\section{HOBBES, T. Leviatán. Madrid: Alianza, 2002.}

INGRAM, A. Viral geopolitics: biosecurity and global health governance. In: DOBSON, A.; BARKER, K.; TAYLOR, S. L. (Ed.). Biosecurity: the Socio-Politics of invasive species and infectious diseases. New York: Routledge, 2013. p. 137-150.

KHAN, A. S. Preparedness 101: Zombie Apocalypse. Public Health Matters Blog. 16 May 2011. Disponible en: <http:// blogs.cdc.gov/publichealthmatters/2011/05/preparedness-101zombie-apocalypse/>. Acceso el: 10 agosto 2015.

LAKOFF, A. Preparing for the next emergency. Public culture, v. 19, n. 2, p. 247-271, 2006.

LAKOFF, A. The generic biothreat, or, how we became unprepared. Cultural Anthropology, v. 23, n. 3, p. 399-428, 2008.

LAKOFF, A. Swine Flu and the Preparedness Apparatus. Newcastle: Keele University, 2009.

LAKOFF, A.; COLLIER, S. Biosecurity interventions: global health and security in question. New York: Columbia University Press, 2008.

LATOUR, B. La esperanza de Pandora: ensayos sobre la realidad de los estudios de la ciencia. Barcelona: Gedisa, 2001.

MARSHALL, T. H. Citizen and social class. London: Cambridge University Press, 1950.

ONG, A. Mutations in citizenship. Theory, Culture \& Society, v. 23, n. 2-3, p. 499-505, May 2006.

O'TOOLE, T. Smallpox: an Attack Scenario. Emerging Infectious Diseases, v. 5, n. 4, p. 540-546, July-Aug. 1999. Disponible en: <http://wwwnc.cdc.gov/eid/article/5/4/pdfs/990416.pdf>. Acceso el: 10 agosto 2015.

PELÁEZ, J. La filosofía marxista sobre la política y otros conceptos de ciudadanía, derechos y libertades. Revista de Derechos Humanos y Estudios Sociales, v. 1, n. 1, p. 37-47, 2009.

PEÑA, J. La ciudadanía. In ARTETA, A.; GARCÍA, E.; MÁIZ, R. (Ed.). Teoría política: poder, moral, democracia. Madrid: Alianza, 2003. p. 215-245.

PETRYNA, A. Biological citizenship: the science and politics of Chernobyl-exposed populations. History of Science Society, v. 19, n. 2, p. 250-265, 2004.

RABINOW, P.; BENNETT, G. Designing Human Practices: an Experiment with Synthetic Biology. Chicago: University of Chicago Press, 2012.

ROSE, N.; NOVAS, C. Biological citizenship. In: ONG, A.; COLLIER, S. (Ed.). Global assemblages: technology, politics and ethics as anthropological problems. Oxford: Blackwell, 2003. p. 439-463. 
ROSE, N. The politics of life itself: biomedicine, power and subjectivity in the twenty-first century. New Jersey: Princeton University Press, 2006.

SAMIMIAN-DARASH, L. A pre-event configuration for biological threats: preparedness and the constitution of biosecurity events. American Ethnologist, v. 36, n. 3, p. 478491, 2009.

SERRES, M. Los cinco sentidos: ciencia, poesía y filosofía del cuerpo. Madrid: Taurus, 2002.

TIRADO, F. Los objetos y el acontecimiento: teoría de la socialidad mínima. Tesis doctoral defendida en la Universitat Autònoma de Barcelona. Bellaterra: UAB, 2001.

WORLD HEALTH ORGANIZATION Communicable disease alert and response for mass gatherings. 2008. Available at: $<$ http://www.who.int/csr/mass gathering/en/>. Access on: 12 Ago. 2015.

ZYLBERMAN, P. Tempêtes microbiennes: essai sur la politique de sécurité sanitaire dans le monde transatlantique. París: Gallimard, 2013.

Recibido: 9 de septiembre el año 2015

Aceptado: 27 julio el año 2016 